\title{
Lean Thinking to Improving Access to Cancer Patients in a Public General Hospital
}

\author{
Carlos Frederico Pinto* \#, Stela Maris Coelho* ", Evelin Araujo Marotta ${ }^{\#}$ \\ Sheila Vianna Reis ${ }^{\#}$, Robisom Damasceno Calado*** \\ and Messias Borges Silva*** \\ * School of Engineering of Guaratinguetá (FEG -UNESP) Guaratinguetá, SP, Brazil, \\ ** School of Engineering of Lorena (EEL-USP) Lorena, SP, Brazil \\ (e-mail: messias@dequi.eel.usp.br) \\ *** School of Management (FA - PUC), Campinas, SP, Brazil \\ (e-mail: robisomcalado@gmail.com) \\ \# Instituto de Oncologia do Vale, São José do Campos, SP \\ Brazil (Tel: +55 12 3924-9055; e-mail: carlosfpinto@iov.com.br)
}

\begin{abstract}
:
Unbalanced treatment scheduling and over-crowding is a common problem for cancer centers in Brazil, with huge access restrictions due to system inefficiencies and poor assistance design. The purpose of this report is to show how lean thinking can be applied to healthcare by using lean methods and production leveling. The case study/report presented was adopted in order to describe the approach, techniques and findings of this project, as part of a lean initiative. Lean Value Stream Mapping tools and leveling tools improved the unit performance by increasing unit capacity freeing treatment slots by leveling and decrease of waiting time for cancer treatment. The process redesign also eliminated unnecessary movement and overtime.
\end{abstract}

\section{Keywords}

Keywords: Lean Manufacturing, Production Control, Queues.

\section{INTRODUCTION}

Lean management principles have been used effectively in manufacturing companies for decades, particularly in Japan. The Institute for Healthcare Improvement believes that lean principles can be successfully applied to the delivery of health care. Even though health care differs in many ways from manufacturing, there are also similarities: Whether building a car or providing health care for a patient, workers must rely on multiple and complex processes to accomplish their tasks and provide value to the customer or patient. Waste of money, time or supplies always decreases value.

According to Soares (2012) the Brazilian government faces serious difficulties in promoting health services to the population. One of the main difficulties is related to the lack of ability to care provided by the public sector, which is related to the gap between the constitutional responsibility and budget availability, since it is not intended resourced and regularly to support a universal system and Full conceived in a context of democratization and political crisis of the state.

Lean thinking in healthcare proposes creation of value and better quality services for the patient and the society. The elimination of non-value added activities along with all other wastes, helps to establish a flow value for the patient, increasing the efficiency of operations, while simultaneously improving the quality of care (Womack, 2003).

According to Womack and Jones (2003), Silberstein (2006), initiatives to implement the Lean philosophy in medical services and healthcare are just beginning. 
The provision of health services has many sources of inefficiency and quality issues that are a real challenge for managers of the area (ARAUJO, 2005).

The study involved the use of lean thinking for the removal of waste and queue management at a public oncology clinic at a public hospital in the city of Taubate, Sao Paulo, Brazil. The Unit of Clinical Oncology, Hospital Regional do Vale do Paraíba (HRVP) faces queues in all process for the treatment. Our aim was to eliminate waste associated with disconnected information flow between sectors, to improve occupation of treatment slots and waiting time for first acess in cancer treatment.

\section{LITERATURE REVIEW}

Lean Thinking is being widely used in UK National Health Services (NHS) (Yousri, 2011) and in several other organizations around the world to improve patient care, safety, access and timeliness. There is no common sense for a definition of lean production (Howleg 2007).

Academic books and articles still struggle to define clear measures for lean production (Shan 2007); one well established and popular tool, Value Stream Mapping (VSM) as proposed by Shook and Rother (1999) is used to identify and analyze, as well as suggest solutions to production problems.

\subsection{Value Stream Map}

The value stream consists to identify "all the value-added and non-value-added actions required to bring a specific product, service, or combination of products and services to a customer; including those in the overall supply chain as well as those in internal operations" (Womack, 1990).

The value stream mapping enables the organization to understand the current process, identify nonadded-value steps and provide a vision of gains and benefits associated with waste removal. The VSM is basically a PDCA cycle (Plan-Do-Check-Act) involving the following simplified steps: identify the value stream (current state); problem analysis; value proposition (future state); action plan (value delivery); and sustainability (action). For problem analysis we used common lean and quality tools: Pareto Analysis; Cause-Effect Diagrams; Affinity Diagrams; Five Whys; and Spaghetti Diagram (Pinto 2010).

\subsection{Leveling production}

In the Brazilian healthcare systems, unbalanced production creates a capacity problem: most units are overcrowded and do not provide coordinated care, with several disconnections through the process. Production leveling, also known as "heijunka" is one fundamental component of the Toyota Production System (Bohnen, 2011). We used Value Stream Mapping (VSM) tool as proposed by Shook and Rother (1999) to identify and analyze problems and smooth our daily production agenda, aiming to reduce or eliminate wastes such as waiting, movement, rework, delays.

\subsection{Kanban}

Is any mechanism to communicate the time to replenish or produce exactly what is being requested and the amount due, enabling the production flow is pulled (Junior et al., 2008; Slack, 2008).

The principal reasons to employ Kanban System instead of computerized system are (Y. Sugimori et al, 2007) 
2.3.1. Reduction of cost processing information. It calls for huge cost to implement a system that provides production schedule to all the processes and suppliers .

2.3.2. Rapid and precise aquisition off acts.

2.3.3. Limiting surplus capacity of preceding shops.

\section{METHODOLOGICAL PROCEDURES}

This is an action research study, where we identified a problem, used problem analysis tools and defined a value proposal, as stated by Shook et al (1999). In this part of the article will be presented in the local case study and service procedures.

\subsection{Scenario Studied}

The Hospital Regional do Vale do Paraiba (HRVP) is a public general hospital in Taubaté, São Paulo State, Brazil covering cancer treatment for a population of 1 million inhabitants from more than 40 cities. The hospital is $100 \%$ public and $2 / 3$ of our patients need governments assistance to travel and get access to HRVP. Most of them travel 1 to 2 hours to get to the hospital or its resources. Waiting time to access is reasonable ( 2 weeks median), but other resources like mammograms, biopsies, CT scans and surgery require long queues. The hospital is responsible for complex care, sharing resources for the cancer center, general surgery, head and neck, cardiovascular and neurosurgery, renal and hypertension centers.

\subsection{Major Problems}

The staging of the disease at the start of treatment is one of the most important factors determining the prognostic of the patient. Thus, delays in diagnosis or treatment allows tumor growth resulting in lower chance of cure for patients.

Improve treatment access by shortening the waiting time for surgery and/or chemotherapy/radiation therapy for cancer patients by $50 \%$. Median waiting time for surgery was 90 days including 5 to 7 visits to the HRVP (Figure 1, three months median waiting time for access). Access to medical oncologist was 114 days from registry.

\subsection{Proposed Actions}

We see circa 250 new breast cancer patients' yearly or 20 new patients monthly. This presentation represents the "pilot" project involving breast cancer patients. We developed a multi professional team involving the outpatient care coordinator, nurse managers and quality managers from the hospital and the cancer center, medical oncologists, breast surgeons, and radio-oncologists. This project was elaborated to focus the needs of the patients leaving in the background the requirements of the various departments involved. The challenge was to make these professionals see and draw how would be an ideal process of caring for these patients. With this vision and the collaboration of 
these professionals, we proposed a new flow, ensuring that no one would have workload with the new changes.

We used the value stream mapping (VSM) to design our current state (Shook, J. Rother, M. Aprendendo a Enxergar, 2a edição, LIB, São Paulo, 2010) to identify the current state, perform the analysis of the problem and propose a future state ideal with a plan to implement and sustain these improvements (a complete PDSA cycle).

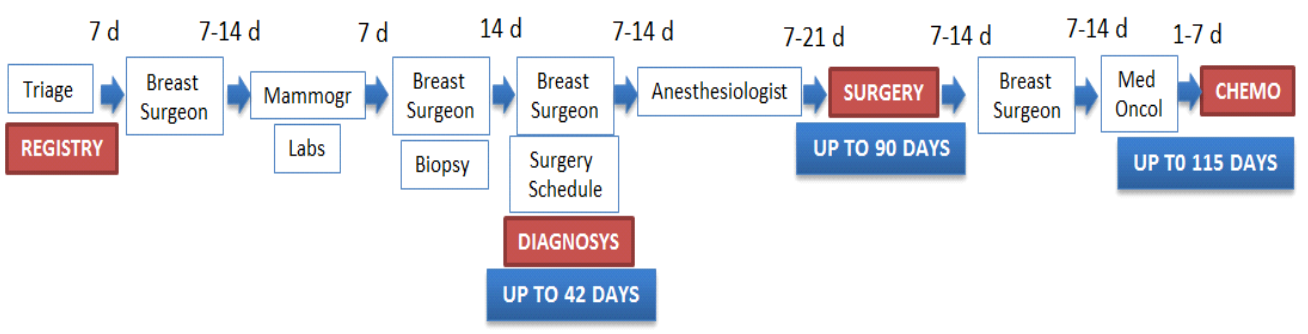

Figure 1: Current state: time line for breast cancer treatment access.

The future state aim was to develop a "FAST TRACK" for newly diagnosed or "highly suspected" breast cancer patients. The track was designed to accomplish 4-7 weeks activities in one single day by coordinating care and patient and processes flow.

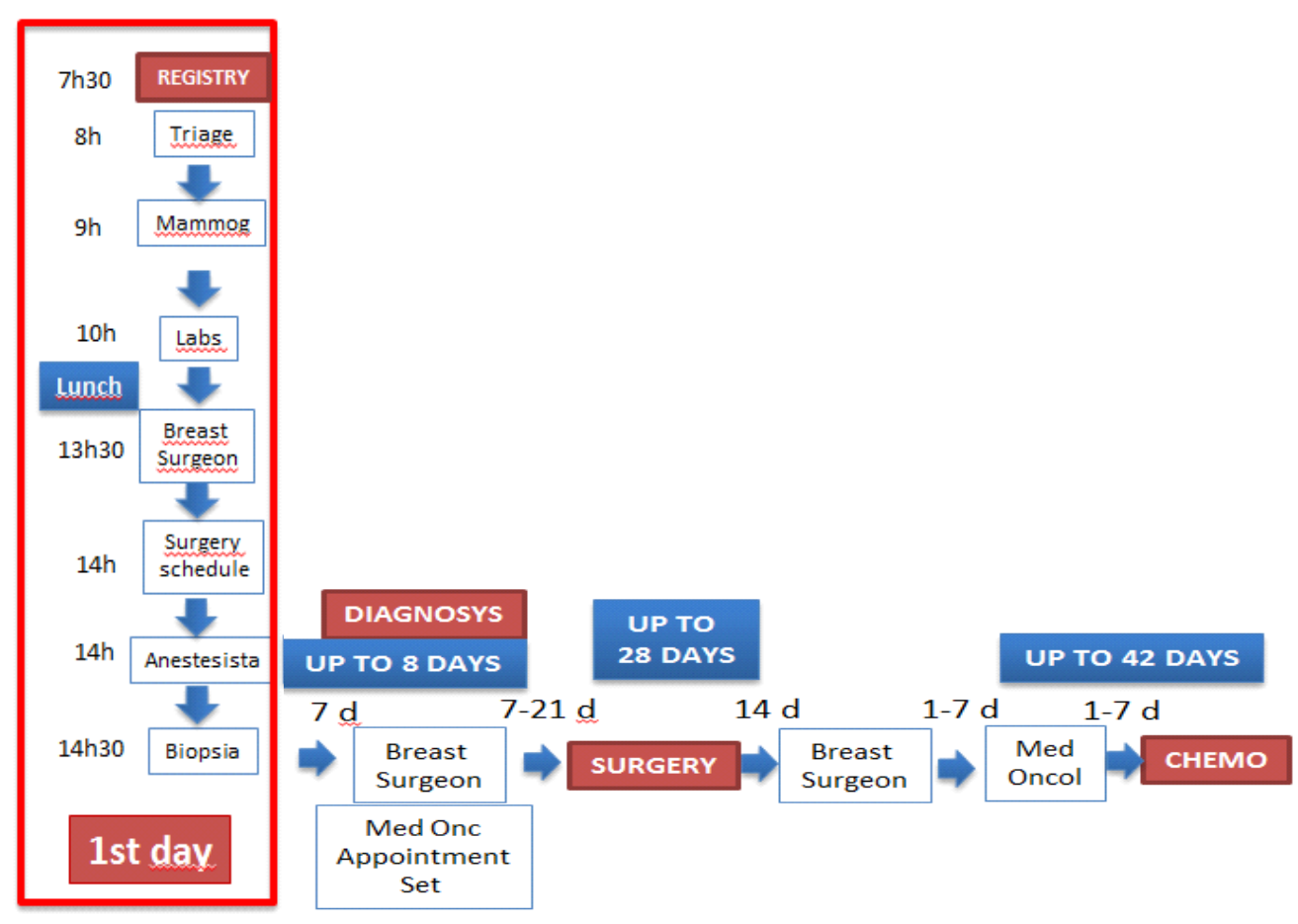

Figure 2: Future State: "FAST TRACK" for breast cancer patients 
To do this, was required three basic interventions:

3.3.1. Establish standard procedures for each type of patient (each new flow);

3.3.2. Redesign the schedules of medical care and examinations;

3.3.3. Establish service agreements between the various actors in the process.

\subsection{Establish standard procedures for each type of patient (each new flow)}

1a. We elaborated a "service flowchart" to direct the flow. It is called " Care Patch Kanban" and follows the patient during the day and is a document which is accessed by all involved in the process. It is checked at every stage, ensuring that all the requirements of that step were met.

1b. 2 flows were defined: The first one for patients without diagnosis but with highly suspected cancer (clinical or imaging exam). The aim of this flow was to perform a biopsy on the same day and plan the definitive surgical treatment in up to 21 days, in order to finish the day with a biopsy.

The second flow for patients already diagnosed with cancer. These patients should plan surgery or, in advanced cases, start neoadjuvant or palliative treatment .

1c. Exams bundles were defined for each of the flows that would be performed in accordance with the predicted sequence for each flow.

\subsection{Redesign the schedules of medical care and examinations:}

2a. The patient care was concentrated in a single day and in one place, changing the times and days of appointments with the experts involved (breast cancer specialist, oncologist, anesthetist and radiation oncologist). The new patients with breast cancer started to have appointments only on Mondays in a dedicated flow. They also had dedicated flow for mammograms, ultrasound, radiological examinations of chest CT scans (for patients with advanced disease), ECGs and laboratory tests according to each bundle of standardized tests and procedures.

\subsection{Establish service agreements between the various actors in the process.}

3a. Agreement 1: "4 open slots on Mondays, every Monday". For the image center (mammograms); lab center (EKG, labs); Anesthesiologist and breast surgeon appointments.

3b. Agreement 2: "2 open slots on Mondays, every Monday". For breast biopsies, 
pathologists and medical oncologists.

3c. Agreement 3: "1 attendant trainee for flow improvement". To guide patients throughout their daylong journey.

3d. Agreement 4: "lunch and rest will be provided for all patients by IOV social services".

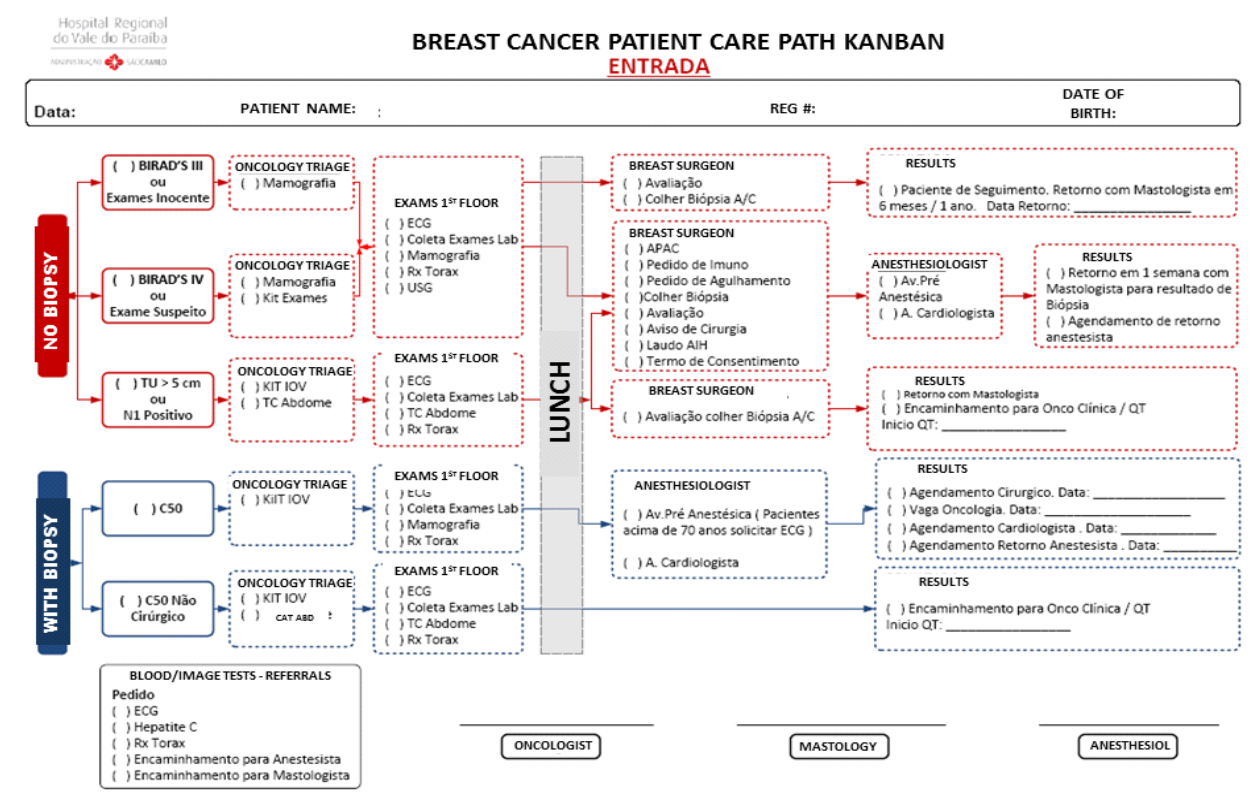

Figure 3: Care-path 1st day kanban

\section{RESULTS}

Between 09/01/2014 to 04/30/2015 were included 120 patients with the following results:

The average waiting time for surgery which was 90 days. Now it is 35 days. Which represented an outcome $61 \%$ better.

The median time to start chemotherapy was 114 days. Now it is 56 days. Which represented an outcome $50 \%$ better.

Develop new agreements to expand the "FAST TRACK" to head and neck cancer patients. Our 2016 challenge is to develop "FAST TRACKS" to breast, head and neck, colorectal and prostate cancer, covering $85 \%$ of our expected cancer patients demand.

A significant reduction in the waiting time for treatment not only ensures faster treatment but also dramatically reduced the number of hospital visits, eliminating between 5-7 visits to begin chemotherapy. This performance not only improves the quality of service but also reduces the physical and emotional distress of patients, and eliminates waste in the value chain as dozens of hours of waiting, unnecessary travel, excessive movement within the hospital and disconnection of the information in care processes. 


\section{CONCLUSION}

Patients diagnosed with cancer treated in public service suffer significant delays at various stages of their diagnoses and cancer treatment. Reduce access to initial treatment seems to be the most effective strategy, but it is imperative that the system has means and organization to act on the abnormalities found in the flow.

The use of the lean tools are able to improve the healthcare flow without adding cost to the process. The project was able to significantly reduce waste in the processes (handling, over-processing, defects, waiting, transport) without increasing the workload for the stakeholders.

\section{REFERENCES:}

Araujo, C. A. S. (2005) Fatores a serem gerenciados para o alcance da qualidade para os clientes internos: um estudo em um conjunto de hospitais brasileiros. Rio de Janeiro: UFRJ/COPPEAD. Tese de Doutorado em Administração,. Disponível em: $<$ http://www.dominiopublico.gov.br/pesquisa/DetalheObraForm.do?select_action=\&co_obra=1 05686>. Acesso em 12 de setembro de 2012.

Bohnen F, Maschek T, Deuse J. (2011). Leveling of low volume and high mix production based on a Group Technology Approach. Journal of Manufacturing Science and Technology 4 247-251.

Holden, RJ (2011). Lean Thinking in Emergency Departments: A Critical Review Annals of Emergency Medicine 57(3)

Holweg M. (2007) The genealogy of lean production. Journal of Operations Management 25420 437

Mazzocato P, Savage C, Brommels H, et al. (2010) Lean thinking in healthcare: a realist review of the literature. Qual Saf Health Care. doi:10.1136/qshc.2009.037986.

Junior et al., 2008; Slack, 2008. Indepent Jounal of Management \& Production (IJM\&P). Acesso em http://www.ijmp.jor.br v. 5, n. 11, august 2015.

ISSN: $2236-269 \mathrm{X}$

DOI: $10.14807 /$ ijmp.v5i4.245

Pinto C, (2010) "Improving Wait Times at a Medical Oncology Unit" in J. Aherne \& J. Whelton, editors, "Applying Lean in Healthcare", Productivity Press, NY.

Shook J and Rother M, (1999) "Learning to See", Lean Enterprise Institute, Boston.

Silberstein, A. C. L. (2006) Um estudo de casos sobre a aplicação de princípios enxutos em serviços de saúde no Brasil. Dissertação (mestrado) - UFRJ/ COPPEAD/ Programa de Pós-graduação em Administração.

Soares, A. Empréstimos externos para o setor saúde no Brasil: soluções ou problemas. Saúde e Sociedade. São Paulo, $2012 . \quad$ Avaliableat: $<$ http://www.scielo.br/scielo.php?pid=S01012902009000600012\&script=sci_arttext $>$. Accessed25/aug/2012.

Spears, S (2005) Fixing Health Care from the Inside, Today. Harvard Business Review Sept.

Womack JP, Byrne AP, Fiume OJ (2005). Going Lean in Health Care. Cambridge, MA: Institute for Healthcare Improvement.

Womack, JP, Jones DT, and Roos D (1990). The Machine That Changed the World. Free Press, New York.

Womack, JP, Jones, DT (2003). Lean Thinking, revised ed. Free Press, New York. 
Y. Sugimori a , K. Kusunoki a , F. Cho a \& S. Uchikawa (2007). Production Control Department, Toyota Motor Co., Ltd , 1 Toyota-cho, Toyota-shi, 47, Japan. International Journal of Production
http://www.tandfonline.com/doi/abs/10.1080/00207547708943149, 11, august 2015.

em

Young T and McClean S. (2008) A critical look at Lean Thinking in healthcare. Qual Saf Health Care 17: 382-386;

Yousri TA, Khan Z, Chakrabarti D, Fernandes R, Wahab R (2011) Lean thinking: Can it improve the outcome of fracture neck of femur patients in a district general hospital? Injury, Int. J. Care Injured 42: 1234-1237. 